\title{
POTENCIAL DE REGENERAÇÃO DE UMA ÁREA INVADIDA POR Pteridium aquilinum NO PARQUE NACIONAL DO CAPARAÓ
}

\author{
Jeane de Fátima Cunha Brandão ${ }^{1 *}$, Sebastião Venâncio Martins ${ }^{1}$, Isac Jonatas Brandão \\ ${ }^{1}$ Universidade Federal de Viçosa, Departamento de Engenharia Florestal, Viçosa, Minas Gerais, Brasil - \\ jeanefcunha@yahoo.com.br*; venancioufv@gmail.com \\ ${ }^{2}$ Universidade Federal de Viçosa, Departamento de Economia, Viçosa, Minas Gerais, Brasil - isacbrand@hotmail.com
}

Recebido para publicação: 10/07/2015 - Aceito para publicação: 13/06/2016

\begin{abstract}
Resumo
Este estudo teve como objetivo investigar a composição de espécies do banco de sementes e esporos do solo de uma área invadida por Pteridium aquilinum e de uma floresta no entorno, a fim de conhecer o potencial de regeneração dessas áreas. Foram coletadas trinta amostras de solo na floresta, trinta amostras de solo na área invadida por $P$. aquilinum e trinta amostras da serapilheira da samambaia, que foram levadas para o Viveiro de Pesquisas, na Universidade Federal de Viçosa. As amostras foram mantidas na casa de vegetação e após a emergência das plântulas, realizou-se a quantificação das espécies arbóreas, arbustivas, herbáceas, trepadeiras e gramíneas. Apenas as espécies arbustivas, arbóreas e a herbácea $P$. aquilinum foram identificadas. Considerando os indivíduos arbustivo-arbóreos, verificou-se a presença de 1.406 no banco de sementes da floresta, 79 no banco de sementes da área invadida pela samambaia e 34 no banco da serapilheira da samambaia. As famílias de maior destaque no banco da floresta foram Salicaceae, Urticaceae e Dennstaedtiaceae. No banco da área invadida por $P$. aquilinum e no banco da serapilheira predominou a família Dennstaedtiaceae, representada por $P$. aquilinum. Os resultados sugerem que a presença de $P$. aquilinum afetou o potencial de regeneração dessa área.

Palavras-chave: Invasão biológica; samambaia; inibição; regeneração; floresta.
\end{abstract}

\begin{abstract}
Regeneration potential of an area invaded by Pteridium aquilinum in the National Park of Caparaó. The purpose of this study was to investigate the species composition of the soil seed and spores bank of an area invaded by $P$. aquilinum and a forest in the vicinity, to understand the regeneration potential of these areas. Thirty soil samples were collected in the forest, 30 in the area dominated by $P$. aquilinum and 30 samples of fern litter, which were taken to a research center of plant nursery at the Federal University of Viçosa. The samples were maintained in a greenhouse and after seedling emergence, the tree, shrub, herb, vine, and grass species were quantified. Only the shrub, tree and the herbaceous species $P$. aquilinum were identified. Considering the shrub-tree individual, 1.406 were detected in the forest seed bank, 79 in the seed bank of the área dominated by bracken and 34 in the bracken litter seed bank. The most prominent families in the forest bank were Salicaceae, Urticaceae and Dennstaedtiaceae. In the bank of the area dominated by $P$. aquilinum and in the litter bank, the family Dennstaedtiaceae was predominant, represented by $P$. aquilinum. The results suggested that the presence of $P$. aquilinum affected the regeneration potential of the study area. Keywords: Biological invasion; bracken; inhibition; regeneration; forest.
\end{abstract}

\section{INTRODUÇÃO}

O banco de sementes do solo compreende as sementes viáveis, em estado de dormência real ou imposta, presentes na superfície ou no interior do solo (MARTINS, 2009a). O banco de esporos, por sua vez, compreende os esporos viáveis armazenados no solo (ESTEVES, 2013).

Tanto o banco de sementes quanto o de esporos estão envolvidos em processos importantes, dentre eles, a manutenção das espécies após distúrbios naturais ou antrópicos (BAIDER et al., 2001; ESTEVES, 2013). Portanto, o estudo dos fatores que controlam a dinâmica desses bancos, como a composição, a densidade e as estratégias das espécies no banco são de fundamental importância para conhecer o potencial de regeneração de um ecossistema que sofreu algum tipo de perturbação. Esse conhecimento, por sua vez, pode auxiliar no desenvolvimento de técnicas de restauração e no monitoramento desses ambientes.

Em florestas tropicais, o banco de sementes do solo é constituído, basicamente, por espécies pioneiras herbáceas e arbustivo-arbóreas de ciclo de vida curto, que atuam como facilitadoras do processo de sucessão ecológica em áreas alteradas. Mas, quando o banco de sementes ou de esporos é composto por elevada densidade

FLOREST A, Curitiba, PR, v. 46, n. 4, p. 543 - 552, out. / dez. 2016.

Brandão, J. de F. C. et al.

ISSN eletrônico 1982-4688

DOI: $10.5380 /$ rf.v46i3.41387 
de espécies exóticas, podem competir com as espécies nativas, diminuindo o potencial de regeneração dos ecossistemas (MARTINS, 2009a).

A espécie Pteridium aquilinum (L.) Kuhn, popularmente conhecida como samambaia do campo ou samambaia, é considerada invasora no Brasil (TAYLOR, 1980), e vem dominando diversas áreas do Parque Nacional do Caparaó, principalmente após a ocorrência de incêndios que, geralmente, são de causa antrópica. Dependendo do grau de infestação, a regeneração natural de espécies arbustivo-arbóreas ocorre sob forte inibição ou pode nem mesmo acontecer. A adaptação de P.aquilinum em ambientes alterados, como em solos ácidos e pobres, além da capacidade que os seus esporos possuem de alcançar áreas distantes com facilidade e rapidez a torna uma potencial invasora.

$\mathrm{Na}$ área do Parque do Caparaó dominada por P. aquilinum, que foi objeto desse estudo, ocorreu um incêndio há 50 anos, formando uma grande clareira, o que contribuiu para a invasão. Desde então, o processo de regeneração encontra-se estagnado, pois a espessa biomassa de serapilheira (um metro de altura) existente na área, aliado a barreira física e química imposta pela extensa rede de rizomas, que liberam exudados tóxicos no solo, vem impedido o estabelecimento das espécies nativas. Assim, a hipótese do trabalho é que a presença de $P$. aquilinum compromete o banco de sementes da área invadida e da floresta no seu entorno.

No Brasil, praticamente inexistem trabalhos sobre o banco de sementes em áreas invadidas por $P$. aquilinum. Portanto, este estudo poderá contribuir para a escolha do manejo mais adequado das áreas invadidas, bem como conhecer o potencial de regeneração da floresta do entorno, caso haja novos distúrbios. Dessa forma, o objetivo do estudo foi avaliar se a presença de $P$. aquilinum compromete o banco de sementes do solo de uma área invadida por esta espécie e no seu entorno, a fim de compreender o potencial de regeneração dessas áreas.

\section{MATERIAL E MÉTODOS}

O trabalho foi realizado no Parque Nacional (PARNA) do Caparaó, que está localizado na divisa entre os estados do Espírito Santo e Minas Gerais. O clima do PARNA do Caparaó é Cwb (Köppen), tropical de altitude. Possui temperaturas amenas, com médias anuais entre os 19 e $22^{\circ} \mathrm{C}$. A pluviosidade está em torno de $1.200 \mathrm{~mm}$ anuais. Os solos dominantes são os Latossolos e o Podzólico, de fertilidade baixa à média (ICMBio, 2015).

$\mathrm{O}$ trecho de Mata Atlântica em que foram coletadas as amostras de solo localiza-se em Minas Gerais $\left(20^{\circ} 25^{\prime} 0,43^{\prime}\right.$ 'S e $41^{\circ} 51^{\prime} 3,78^{\prime}$ W), possui altitude 1.345 metros e é classificado como Floresta Estacional Semidecidual Montana (IBGE, 2012) estando em processo de regeneração desde 1961, quando foi criado o PARNA do Caparaó.

A coleta das amostras de solo e serapilheira foram realizadas em duas áreas. Uma representa uma grande clareira de aproximadamente três hectares e encontra-se completamente invadida por $P$. aquilinum, não existindo nenhum tipo de vegetação nativa. Há indícios de que a invasão de $P$. aquilinum aconteceu após a ocorrência de incêndio florestal, há cerca de cinquenta anos. Nessa clareira, foram coletadas, separadamente, amostras de solo e amostras da serapilheira de P. aquilinum. A outra coleta foi realizada em uma floresta em estágio médio de regeneração no entorno da área invadida por $P$. aquilinum, sendo que, nessa área, foi coletada apenas amostras de solo. Anteriormente a criação do PARNA do Caparaó, a área da floresta era utilizada para pastagem e a área invadida por $P$. aquilinum foi utilizada para cultivo de frutíferas.

$\mathrm{Na}$ área invadida por $P$. aquilinum, foram dispostas trinta parcelas equidistantes em cinco metros uma das outras, onde foram coletadas trinta amostras de solo e trinta amostras da serapilheira, separadamente, perfazendo um total de sessenta amostras. Na floresta do entorno da área invadida por P. aquilinum foram coletadas trinta amostras de solo, de forma aleatória, a uma distância de até cinquenta metros da borda da floresta.

As amostras do solo e serapilheira foram retiradas com o auxílio de uma moldura de PVC ( 0,25 x 0,40 metros). $\mathrm{Na}$ área interna de cada moldura coletou-se a camada de solo superficial e da serapilheira até uma profundidade de $5,0 \mathrm{~cm}$. As amostras foram colocadas em sacos plásticos e transportadas para o Viveiro de Pesquisas do Departamento de Engenharia Florestal na Universidade Federal de Viçosa.

As amostras foram colocadas em 90 bandejas plásticas perfuradas de dimensões $0,25 \times 0,40 \times 0,05 \mathrm{~m}$, totalizando um volume de solo de $0,15 \mathrm{~m}^{3}$ em uma área $3,0 \mathrm{~m}^{2}$, para cada ambiente. As bandejas foram mantidas na casa de vegetação, por seis meses, sob tela tipo sombrite com $50 \%$ de sombreamento e aspersão automática de água de torneira, quatro vezes por dia, com duração de três minutos cada. Uma vez por mês, eram realizados rodízios das bandejas, para garantir que todas estivessem submetidas a semelhantes condições ambientais.

Após a emergência das plântulas, realizou-se a quantificação das espécies arbóreas, arbustivas, herbáceas, trepadeiras e gramíneas. Mas, foram identificadas apenas as espécies arbustivas-arbóreas presentes no banco de sementes e a herbácea $P$. aquilinum presente no banco de esporos, com o auxílio de especialistas, de bibliografia especializada e consulta no herbário da Universidade Federal de Viçosa. As espécies foram classificadas em famílias e tiveram os nomes científicos e seus respectivos autores atualizados pela base de dados do Missouri Botanical Garden, através do site www.tropicos.org, de acordo com o sistema do Angiosperm Phylogeny Group III (APG III, 2009). As espécies foram classificadas quanto à forma de vida (árvore, arbusto, 
herbácea, gramíneas e trepadeiras), síndromes de dispersão (zoocoria, anemocoria e autocoria) e grupo sucessional (pioneira, secundária inicial e secundária tardia). As avaliações do banco de sementes e esporos foram feitas quinzenalmente por seis meses, sendo que o solo das bandejas foi revolvido, a cada avaliação.

Foram calculados o somatório de indivíduos e de espécies, das formas de vida, das categorias sucessionais e das síndromes de dispersão. As médias do número de indivíduos e de espécies arbustivo-arbóreos do banco de sementes da floresta, da área invadida por $P$. aquilinum e da serapilheira foram comparados através de Análise de Variância (ANOVA), utilizando-se o teste F e posteriormente aplicou-se o teste de Tukey, em nível de $5 \%$ de significância. A mesma comparação foi realizada para o número de indíviduos de $P$. aquilinum no banco de esporos da floresta, da área invadida por $P$. aquilinum e da serapilheira. As análises estatísticas foram realizadas com o auxílio do Software STATISTICA 7.0 (STATSOFT, 2007).

Também foram calculados os parâmetros fitossociológicos densidade e freqüência em valores absolutos e relativos, o índice de diversidade de Shannon-Wiener (H') e a equabilidade (J') utilizando o Software FITOPAC 2.1 (SHEPHERD, 2010).

\section{RESULTADOS}

Foram contabilizados 6.759 indivíduos $\left(2.307 \mathrm{ind} . / \mathrm{m}^{2}\right)$ no banco sob a floresta (entorno da área invadida por Pteridium aquilinum), 2.087 indivíduos (713 ind. $/ \mathrm{m}^{2}$ ) no banco sob a área invadida pela samambaia e 724 indivíduos (247 ind. $/ \mathrm{m}^{2}$ ) no banco da serapilheira da samambaia (Tabela 1).

Tabela 1. Espécies amostradas no banco de sementes e de esporos do solo sob a floresta (Banco Floresta), sob a área invadida por $P$. aquilinum (Banco Samambaia) e em serapilheira de $P$. aquilinum (Banco Serapilheira) no Parque Nacional do Caparaó, MG e caracterização quanto à forma de vida (FV), grupo ecológico (GE) e síndrome de dispersão (SD). Arv. = árvore, Arb. = Arbusto; $\mathrm{P}=$ pioneira, $\mathrm{Si}=$ secundária inicial, $\mathrm{St}=$ secundária tardia; Zoo. = zoocoria, Ane. $=$ anemocoria, Aut. = autocoria; Her. = Herbácea, Gra.= gramíneas, Ter. = trepadeiras. NI = não identificadas. Números entre parênteses indicam a densidade de indivíduos por espécies.

Table 1. Species sampled in the soil seed and spores bank in the forest (Forest Bank), in the area invaded by P. aquilinum (Bracken Bank) and in the P. aquilinum litter (Litter Bank) in the National Park of Caparaó, MG and characterization as the life-form (FV) ecological group (GE) and dispersal syndrome (DS). Arv. = Tree, Arb. $=$ shrub; $\mathrm{P}=$ pioneer, $\mathrm{Si}=$ initial secondary, $\mathrm{St}=$ late secondary; Zoo. = zoochory, Ane. $=$ anemochory, Aut = autochory.; Her. herbaceous, Gra. = grasses, Ter = climbing plants. $\mathrm{NI}=$ not identified. Numbers in parentheses indicate the density of individuals per species.

\begin{tabular}{|c|c|c|c|c|c|c|}
\hline Família/Espécie & FV & GE & SD & $\begin{array}{c}\text { Banco } \\
\text { Floresta }\end{array}$ & $\begin{array}{c}\text { Banco } \\
\text { Samambaia }\end{array}$ & $\begin{array}{c}\text { Banco } \\
\text { Serapilheira }\end{array}$ \\
\hline \multicolumn{7}{|l|}{ Asteraceae } \\
\hline Vernonanthura diffusa (Less.) H. Rob. & Arv & $\mathrm{P}$ & Ane & $(59)$ & (5) & $(0)$ \\
\hline Vernonia polyanthes (Spreng.) Less & Arv & $\mathrm{P}$ & Ane & $(46)$ & (1) & (1) \\
\hline $\begin{array}{l}\text { Piptocarpha macropoda (DC.) Baker } \\
\text { Cannabaceae }\end{array}$ & Arv & $\mathrm{P}$ & Zoo & $(1)$ & (1) & $(2)$ \\
\hline $\begin{array}{l}\text { Trema micrantha }(\text { L. }) \text { Blume } \\
\text { Dennstaedtiaceae }\end{array}$ & Arv & $\mathrm{P}$ & Zoo & $(85)$ & (1) & (1) \\
\hline $\begin{array}{l}\text { Pteridium aquilinum (L.) Kuhn } \\
\text { Euphorbiaceae }\end{array}$ & Her & $\mathrm{P}$ & Ane & $(156)$ & $(184)$ & $(160)$ \\
\hline Alchornea glandulosa Poepp. & Arv & $\mathrm{P}$ & Zoo & $(4)$ & $(0)$ & $(0)$ \\
\hline Croton urucurana Baill. & Arv & $\mathrm{P}$ & Zoo & $(56)$ & $(0)$ & $(0)$ \\
\hline $\begin{array}{l}\text { Sapium glandulatum (Vell.) Pax } \\
\text { Fabaceae }\end{array}$ & Arv & $\mathrm{P}$ & Zoo & (3) & $(0)$ & $(0)$ \\
\hline Apuleia leiocarpa (Vogel) J. F. Macbr. & Arv & $\mathrm{Si}$ & Ane & (1) & $(0)$ & $(0)$ \\
\hline Senna alata (L.) Roxb. & Arb & $\mathrm{P}$ & Aut & (1) & $(0)$ & $(0)$ \\
\hline $\begin{array}{l}\text { Senna macranthera (DC.ex collad) } H . \\
\text { S. Irwin\& Barney }\end{array}$ & Arv & $\mathrm{P}$ & Aut & (2) & $(0)$ & $(0)$ \\
\hline $\begin{array}{l}\text { Senna multijuga (Rich) H. S. Irwin\& } \\
\text { Barney }\end{array}$ & Arv & $\mathrm{Si}$ & Aut & (2) & $(0)$ & $(0)$ \\
\hline Hyperaceae & & & & & & \\
\hline $\begin{array}{l}\text { Vismia guianensis (Aubl.) Choisy } \\
\text { Malvaceae }\end{array}$ & Arv & $\mathrm{P}$ & Zoo & (4) & (1) & $(2)$ \\
\hline Luehea grandiflora Mart. & Arv & $\mathrm{Si}$ & Ane & $(0)$ & $(0)$ & (1) \\
\hline
\end{tabular}

FLORESTA, Curitiba, PR, v. 46, n. 4, p. 543 - 552, out. / dez. 2016.

Brandão, J. de F. C. et al.

ISSN eletrônico 1982-4688

DOI: $10.5380 /$ rf.v46i3.41387 


\begin{tabular}{|c|c|c|c|c|c|c|}
\hline $\begin{array}{l}\text { Triumfetta bartramia } L . \\
\text { Melastomataceae }\end{array}$ & Arb & $\mathrm{P}$ & Zoo & (68) & $(0)$ & (1) \\
\hline Leandra niangaeformis Cogn. & Arb & $\mathrm{P}$ & Zoo & (66) & (14) & (5) \\
\hline Leandra purpurascens (D.C) Cogn. & Arb & $\mathrm{P}$ & Zoo & (82) & (30) & (3) \\
\hline Miconia cinamomifolia (D.C)Naudin & Arv & $\mathrm{P}$ & Zoo & (74) & (3) & (3) \\
\hline $\begin{array}{l}\text { Tibouchina granulosa (Desr.) Cogn } \\
\text { Meliaceae }\end{array}$ & Arv & $\mathrm{P}$ & Zoo & $(0)$ & (1) & (1) \\
\hline $\begin{array}{l}\text { Trichilia pallida } S w . \\
\text { Myrtaceae }\end{array}$ & Arv & St & Zoo & (1) & (0) & (0) \\
\hline $\begin{array}{l}\text { Myrcia rostrata Dc. } \\
\text { Piperaceae }\end{array}$ & Arb & $\mathrm{P}$ & Zoo & (1) & (0) & $(0)$ \\
\hline $\begin{array}{l}\text { Piper umbellatum } L . \\
\text { Rosaceae }\end{array}$ & Arb & $\mathrm{P}$ & Zoo & (128) & (0) & (1) \\
\hline $\begin{array}{l}\text { Prunus sellowii Koehne } \\
\text { Rutaceae }\end{array}$ & Arv & $\mathrm{Si}$ & Zoo & (34) & (1) & (0) \\
\hline $\begin{array}{l}\text { Dictyoloma vandellianum A. H. L. } \\
\text { Juss } \\
\text { Salicaceae }\end{array}$ & Arv & $\mathrm{Si}$ & Ane & (3) & (0) & (2) \\
\hline $\begin{array}{l}\text { Casearia Sylvestris } S w . \\
\text { Solanaceae }\end{array}$ & Arv & $\mathrm{P}$ & Zoo & (291) & (1) & (1) \\
\hline Solanum cernuum vell. & Arb & $\mathrm{P}$ & Zoo & (10) & (3) & $(0)$ \\
\hline Solanum mauritianum Scop. & Arv & $\mathrm{P}$ & Zoo & (113) & (0) & (0) \\
\hline $\begin{array}{l}\text { Solanum sp. } \\
\text { Urticaceae }\end{array}$ & Arv & $\mathrm{P}$ & Zoo & (1) & (0) & (0) \\
\hline Cecropia hololeuca Miq. & Arv & $\mathrm{P}$ & Zoo & (270) & $(17$ & (10) \\
\hline NI 1 & Her & - & - & $(2280)$ & (1098) & (485) \\
\hline NI 2 & Gra & - & - & (2816) & (0) & (44) \\
\hline NI 3 & Tre & - & - & $(101)$ & (726) & (1) \\
\hline TOTAL & & & & 6759 & 2087 & 724 \\
\hline
\end{tabular}

No geral, as formas de vida mais representativas foram as gramíneas, herbáceas e trepadeiras (Tabela 2), sendo que no banco sob a floresta predominaram gramíneas $(41,7 \%)$ e herbáceas $(36,0 \%)$, no banco sob a área invadida por $P$. aquilinum, herbáceas $(61,4 \%)$ e trepadeiras $(34,8 \%)$ e no banco da serapilheira da samambaia, herbáceas $(89,1 \%)$ e gramíneas $(6,1 \%)$.

Considerando os indivíduos identificados (arbustivo-arbóreos e $P$. aquilinum), o grupo ecológico de maior destaque foi o das pioneiras com $97,38 \%$ no banco sob a floresta, $99,6 \%$ no banco sob a área invadida por P. aquilinum e $98,45 \%$ no banco da serapilheira da samambaia. Em nível de espécies, também obteve destaque as pioneiras, variando de 81 a $93 \%$ em cada local (Tabela 2). Não foi observada nenhuma espécie secundária tardia no banco da área invadida por $P$. aquilinum e no banco da serapilheira.

Com relação ao número de indivíduos, destacou-se a dispersão zoocórica no banco sob a floresta (70,37\%) e anemocórica no banco sob a área invadida pela samambaia $(72,24 \%)$ e no banco da serapilheira da samambaia $(84,54 \%)$. Em nível de espécies, destacou-se a dispersão zoocórica no banco sob a floresta $(70,37 \%)$, no banco sob a área invadida pela samambaia $(78,57 \%)$ e no banco da serapilheira da samambaia $(73,33 \%)$. Em seguida, destacaram-se as espécies com dispersão anemocórica, em todas as áreas (Tabela 2).

Considerando apenas os indivíduos arbustivo-arbóreos, no banco de sementes sob a floresta foi registrada a presença de 1.406 indivíduos, pertencentes a 26 espécies, 22 gêneros e 15 famílias. No banco de sementes sob a área invadida por $P$. aquilinum, observaram-se 79 indivíduos, pertencentes a 13 espécies, 11 gêneros e oito famílias botânicas e no banco de sementes da serapilheira de P. aquilinum, 34 indivíduos, pertencentes a 14 espécies, 13 gêneros e nove famílias (Tabela 1), havendo diferença estatística significativa $(p<0,05)$ entre áreas estudadas (Figura 1).

Ao comparar a média do número de indivíduos de $P$. aquilinum no banco de esporos sob a floresta, sob a área dominada por $P$. aquilinum e na serapilheira da samambaia, verificou-se que não houve diferença estatística significativa $(p<0,05)$. Na floresta e na serapilheira da samambaia foram amostrados cinco indivíduos/parcela e na área invadida por $P$. aquilinum seis indivíduos/parcela. 
Tabela 2. Distribuição, por forma de vida, grupo ecológico e síndrome de dispersão das espécies e indivíduos (entre parênteses) no banco de sementes e esporos do solo sob floresta (Banco Floresta), sob a área invadida por P. aquilinum (Banco Samambaia) e em serapilheira de P. aquilinum (Banco Serapilheira) no Parque Nacional do Caparaó, MG.

Table 2. Distribution, by life-form, ecological group and dispersion syndrome of species and individuals (in parentheses) in the soil seed and spores bank in the forest (Forest Bank), in the area invaded by $P$. aquilinum (Bracken Bank) and in the P. aquilinum litter (Litter Bank) in the National Park of Caparaó, MG.

\begin{tabular}{|c|c|c|c|}
\hline Forma de vida & Banco Floresta & Banco Samambaia & Banco Serapilheira \\
\hline Árvore & $19(1050)$ & $10(32)$ & $10(24)$ \\
\hline Arbusto & $7(356)$ & $3(47)$ & $4(10)$ \\
\hline Herbácea & $-(2280)$ & - (1098) & $-(485)$ \\
\hline Gramíneas & $-(2816)$ & $-(0)$ & $-(44)$ \\
\hline Herb./Pteridófitas & $1(156)$ & $1(184)$ & $1(160)$ \\
\hline Cipós/Trepadeiras & $-(101)$ & $-(726)$ & $-(1)$ \\
\hline \multicolumn{4}{|l|}{ Grupo ecológico } \\
\hline Pioneiras & $22(1521)$ & $13(262)$ & $13(191)$ \\
\hline Secundária inicial & $4(40)$ & $1(1)$ & $2(3)$ \\
\hline Secundária tardia & $1(1)$ & $0(0)$ & $0(0)$ \\
\hline \multicolumn{4}{|c|}{ Síndrome de dispersão } \\
\hline Zoocoria & $19(1292)$ & $11(73)$ & $11(30)$ \\
\hline Anemocoria & $5(265)$ & $3(190)$ & $4(164)$ \\
\hline Autocoria & $3(5)$ & $0(0)$ & $0(0)$ \\
\hline
\end{tabular}

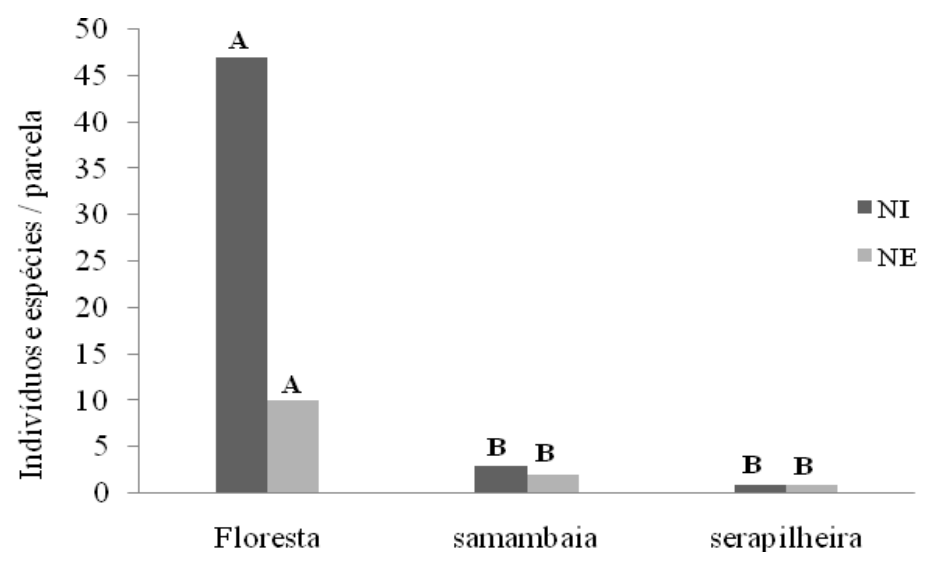

Figura 1. Média do número de indivíduos (NI) e do número de espécies (NE) arbustivo-arbóreas amostradas no banco de sementes do solo sob a floresta (Floresta), sob a área invadida por $P$. aquilinum (Samambaia) e em serapilheira de $P$. aquilinum (Serapilheira) no Parque Nacional do Caparaó, MG. Médias seguidas de letras diferentes diferem significativamente entre si, ao nível de 5\% de significância pelo Teste de Tukey. Desvios padrão para número de indivíduos e espécies, respectivamente: floresta $=6,2$ e 1,2; samambaia $=0,6$ e 0,4; serapilheira $=0,3$ e 0,2.

Figure 1. Mean number of plants (NI) and of shrub-tree species (NE) sampled in the soil seed and spores bank in the forest (Forest Bank), in the area invaded by $P$. aquilinum (Bracken Bank) and in the P. aquilinum litter (Litter Bank) in the National Park of Caparaó, MG. Means followed by different letters differ significantly at $5 \%$ significance by the Tukey test. Standard deviations for the number of individuals and species, respectively: Forest $=6.2$ and 1.2 ; fern $=0.6$ and 0.4 ; litter $=0.3$ and 0.2 .

Com exceção do índice de diversidade de Shannon (H') encontrado para o banco da floresta $(2,53)$, os valores encontrados na área invadida por Pteridium $(1,16)$ e da serapilheira $(0,87)$ mostraram que estas áreas possuem uma diversidade baixa.

No banco da floresta do entorno da área invadida por $P$. aquilinum, as espécies Casearia sylvestris e Cecropia hololeuca obtiveram maior densidade e freqüência (Figura 2A). P. aquilinum apresentou a terceira maior densidade $(10,0 \%)$, mas quanto à freqüência nas parcelas ocupou o sétimo lugar $(6,1 \%)$, juntamente com 
Leandra niangaeformis e Miconia cinnamomifolia, que obtiveram a mesma freqüência (6,1\%). Piper umbellatum obteve a quarta maior densidade $(8,2 \%)$ e a terceira maior frequiência $(8,0 \%)$, juntamente com Trema micrantha, que apresentou a mesma freqüência $(8,0 \%)$.

As famílias com maior densidade no banco da floresta foram Salicaceae $(18,6 \%)$ e Urticaceae $(13,3 \%)$, ambas com apenas uma espécie, sendo Casearia sylvestris e Cecropia hololeuca, respectivamente. A família Melastomataceae ocupou o terceiro lugar no que diz respeito a densidade $(14,2 \%)$ e primeiro lugar em relação a freqüência $(11,2 \%)$, juntamente com Salicaceae que também obteve freqüência de 11,2\%. A família Dennstaedtiaceae, representada apenas por P. aquilinum, ficou em quarto lugar quanto a densidade e oitavo lugar em relação a freqüência (Figura $2 \mathrm{~B}$ ).
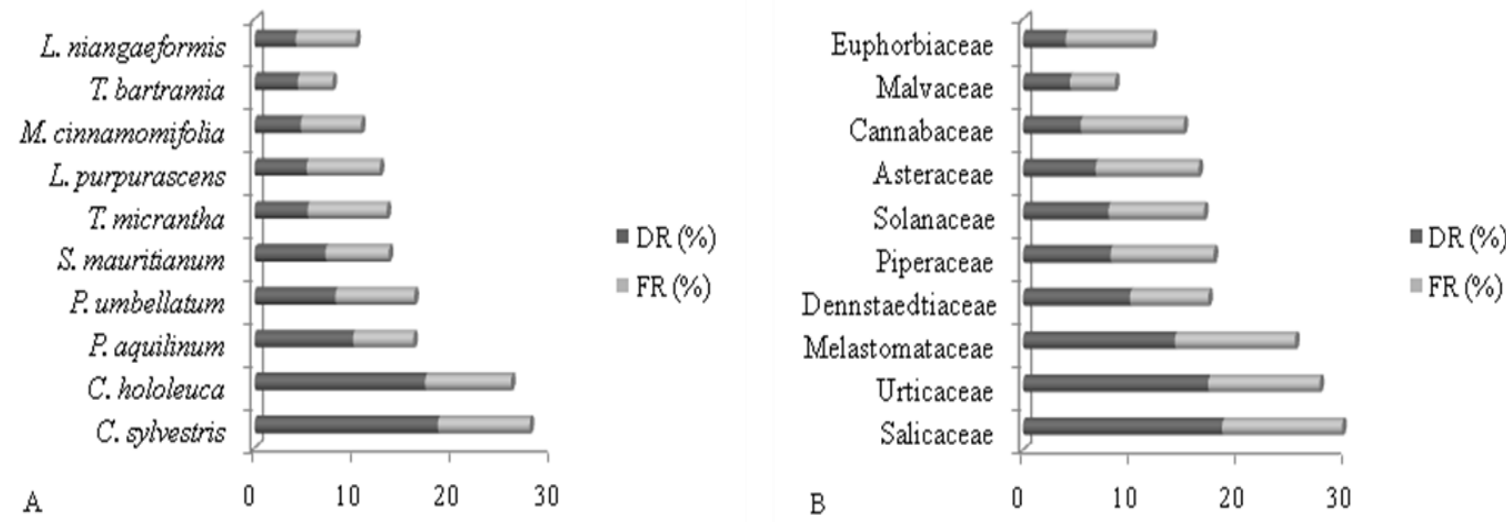

Figura 2. Densidade relativa (DR) e frequência relativa (FR) para as principais espécies (A) e famílias (B) recrutadas no banco de sementes e de esporos do solo sob a floresta no Parque Nacional do Caparaó, MG.

Figure 2. Relative density (DR) and relative frequency (FR) of the main species (A) and families (B) recruited in the soil seed and spores bank in the forest in the National Park of Caparaó, MG.
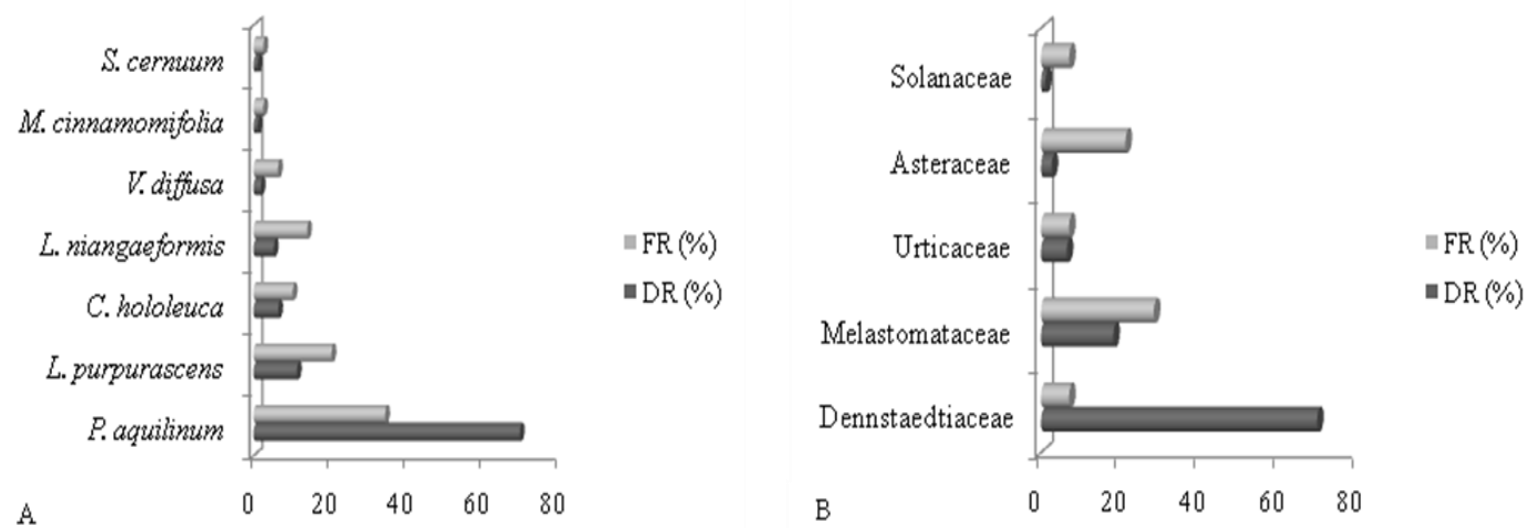

Figura 3. Densidade relativa (DR) e frequência relativa (FR) para as principais espécies (A) e famílias (B) recrutadas no banco de sementes e de esporos do solo sob a área invadida por $P$. aquilinum no Parque Nacional do Caparaó, MG.

Figure 3. Relative density (DR) and relative frequency (FR) for the main species (A) and families (B) recruited in the soil seed and spores bank in the area invaded by P. aquilinum in the National Park of Caparaó, MG.

Quanto ao banco da área invadida por $P$. aquilinum e da serapilheira, observou-se que 70 a $83 \%$ dos indivíduos pertencem a essa espécie. A samambaia também foi mais freqüente nas parcelas, tanto da área invadida por $P$. aquilinum quanto na serapilheira (Figura 3A e 4A). A família Dennstaedtiaceae, representada apenas por $P$. aquilinum, foi a mais numerosa, mas em relação a freqüência, a família melastomataceae, representada por Leandra niangaeformis, Leandra purpurascens, Miconia cinnamomifolia e Tibouchina granulosa, teve maior destaque (Figura 3B e 4B). 

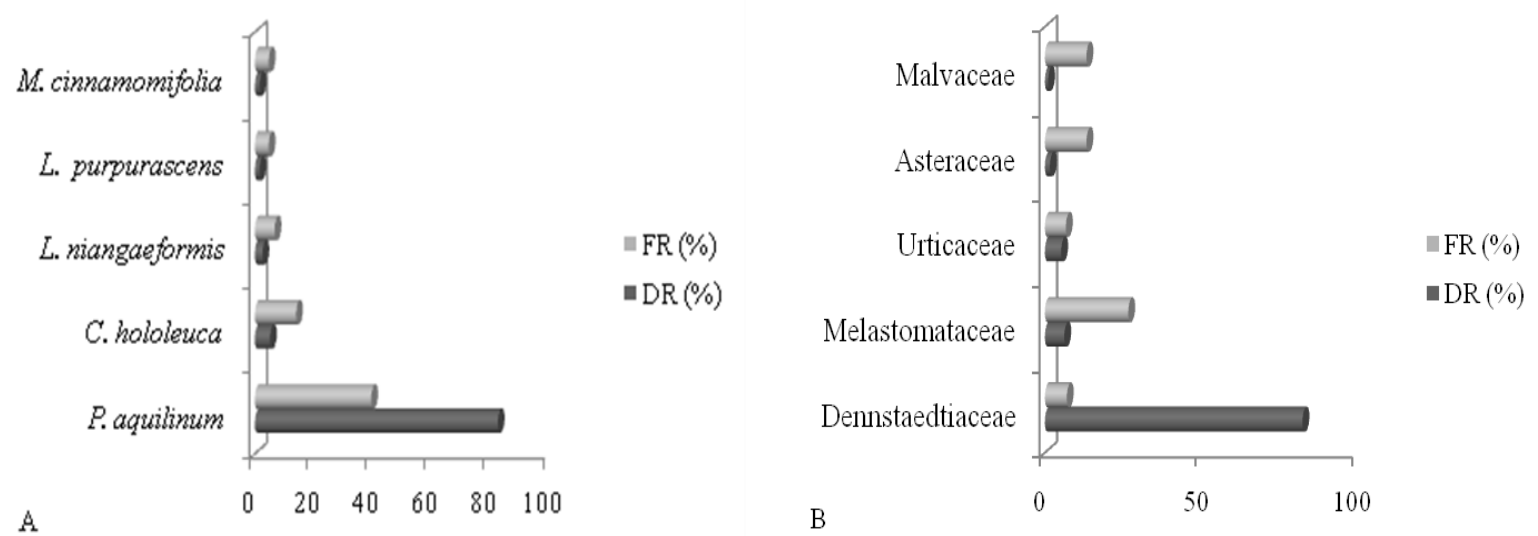

Figura 4. Densidade relativa (DR) e frequência relativa (FR) para as principais espécies (A) e famílias (B) recrutadas no banco de sementes e esporos em serapilheira de $P$. aquilinum no Parque Nacional do Caparaó, MG.

Figure 4. Relative density (DR) and relative frequency (FR) of the main species (A) and families (B) recruited in the $P$. aquilinum litter in the National Park of Caparaó, MG.

\section{DISCUSSÃO}

A variação na densidade de sementes no solo está relacionada, entre outros fatores, com o estádio sucessional, o histórico de perturbação da área, o bioma onde está inserida a floresta e a sazonalidade do banco de sementes. Em florestas secundárias, como é o caso das áreas desse estudo, é esperado que ocorra maior densidade de sementes, pois o dossel mais aberto possibilita maior densidade de espécies pioneiras que forma o banco persistente (BAIDER et al., 2001). Esses autores consideraram ainda que, à medida que a floresta se torna madura, há redução na densidade total das sementes viáveis, principalmente das pioneiras.

Silva e Silva-Matos (2006) estudando uma área que sofreu incêndio na Mata Atlântica, e que posteriormente foi invadida por gramíneas e $P$. aquilinum, encontraram densidade em torno de 857 ind. $/ \mathrm{m}^{2}$, sendo resultados superiores ao encontrado neste estudo para a área invadida por $P$. aquilinum $\left(713\right.$ ind. $\left./ \mathrm{m}^{2}\right)$. $\mathrm{O}$ incêndio na área do estudo de Silva e Silva-Matos (2006) ocorreu há 17 anos e na área deste estudo ocorreu há mais de 50 anos. Então, a camada de serapilheira no local deste estudo tende a ser maior, podendo interferir na densidade de sementes. O menor valor de densidade na área invadida por P. aquilinum (713 ind. $\left./ \mathrm{m}^{2}\right)$, quando comparado à floresta em seu entorno $\left(2.307\right.$ ind. $\left./ \mathrm{m}^{2}\right)$, também pode ser devido à dificuldade das sementes em atingirem o solo em função da densa camada de biomassa da samambaia formada na área.

A presença de grande quantidade de sementes de espécies herbáceas, gramíneas e trepadeiras no banco de sementes do solo, amostradas neste estudo, pode estar relacionada com o ciclo de vida dessas espécies, a grande produtividade de sementes, mecanismos eficientes de dispersão e um dossel mais aberto da floresta secundária, que pode facilitar a dispersão e a incorporação das suas sementes no solo. O predomínio de espécies herbáceas, em florestas secundárias, também foi observado por Baider et al. (2001).

O histórico de uso do solo contribui para a composição do banco de sementes, sendo que áreas com vegetação secundária que já foram utilizadas para atividades antrópicas podem possuir banco de sementes formado principalmente por gramíneas ou espécies herbáceas ruderais, as quais permanecem ali por vários anos (VINHA et al., 2011). Anteriormente a criação do Parque Nacional do Caparaó, a área da floresta era utilizada para pastagem e a área invadida por $P$. aquilinum foi utilizada para cultivo de frutíferas com histórico de ocorrência de incêndio, ou seja, a clareira na floresta atualmente ocupada pela samambaia resultou de atividades antrópicas que favoreceram a invasão pela espécie.

Quando uma floresta sofre um distúrbio, a sucessão secundária se encarrega de promover a colonização da área aberta e conduzir a vegetação através de uma série de estádios (MARTINS, 2009a), dominados, inicialmente, por herbáceas, seguidas por arbustos e árvores pioneiras, as quais desempenham um papel fundamental no estabelecimento das espécies que irão compor a floresta madura (BAIDER et al., 2001). Então, as herbáceas têm a função de reiniciar o processo de sucessão através da ocupação dos espaços abertos na comunidade de plantas. Porém, a grande densidade de plantas herbáceas, principalmente $P$. aquilinum, presentes neste estudo, pode inibir a regeneração natural das espécies arbustivo-arbóreas, mesmo que estas estejam presentes no banco de sementes do solo ou que cheguem a área, via dispersão de sementes (MARTINS, 2009a).

FLOREST A, Curitiba, PR, v. 46, n. 4, p. 543 - 552, out. / dez. 2016.

Brandão, J. de F. C. et al.

ISSN eletrônico 1982-4688

DOI: $10.5380 /$ rf.v46i3.41387 
Os resultados mostram que o potencial de regeneração da área invadida pela samambaia está comprometida, tendo em vista que houve uma redução significativa tanto em nível de indivíduos como de espécies arbustivo-arbóreas ao se comparar com o banco da floresta, mesmo após um longo período de tempo (50 anos). O que evidencia o caráter inibidor do processo de sucessão exercido por $P$. aquilinum. Em alguns estudos realizados em áreas invadidas por $P$. aquilinum também foi constatada uma baixa diversidade de espécies arbustivo-arbóreas no banco de sementes e predominância de espécies com banco persistente e com propágulos de pequenas dimensões (SILVA; SILVA-MATOS, 2006).

A pequena quantidade de indivíduos arbustivo-arbóreos e a baixa diversidade no banco de sementes da área invadida por $P$. aquilinum podem ser atribuídas, principalmente, a densa camada de serapilheira (até 1,0 m) formada pela samambaia, que impede a chegada de sementes no solo, além de reduzir a radiação solar no nível do solo dificultando a germinação e estabelecimento de espécies arbustivo-arbóreas (RIBEIRO et al., 2013).

$\mathrm{Na}$ área invadida por $P$. aquilium, houve ocorrência de fogo antes da sua invasão e de acordo com alguns estudos (SILVA; SILVA-MATOS, 2006) isso contribui para o empobrecimento do banco de sementes, com aumento da presença de espécies invasoras e redução das espécies nativas. Somado a isso, a elevada produção anual de biomassa seca de $P$. aquilinum pode aumentar a intensidade e a frequiência das queimadas, o que pode empobrecer ainda mais o banco de sementes. Portanto, a invasão de $P$. aquilinum pode modificar a estrutura e a composição florística do componente arbustivo-arbóreo em áreas com incêndios frequentes.

A proximidade de fontes de propágulos pode influenciar positivamente a composição do banco de sementes (MARTINS 2009a), favorecendo a regeneração natural. Mas no caso da área invadida por $P$. aquilinum, os propágulos provenientes da floresta não garantirão a regeneração natural da área, pois além das sementes não chegarem ao solo, a serapilheira também se tornou uma barreira para a germinação das poucas sementes existentes no banco. Dessa forma, a retirada da serapilheira e a recomposição da vegetação arbórea tornam-se essenciais para desencadear a sucessão nessa área.

Na floresta no entorno da área com samambaia, foi amostrada apenas uma espécie secundária tardia. A baixa proporção de espécies tardias no banco de sementes da floresta pode ser devido à dormência facultativa dessas espécies, que podem germinar rapidamente e compor o banco de plântulas ou permanecer dormentes diante de condições adversas ou porque espécies mais tardias produzem sementes grandes e em menor quantidade, sendo mais difíceis de serem incorporadas ao solo, ficando sujeitas a predação.

O banco de sementes de áreas alteradas natural ou antropicamente contribui principalmente para a regeneração das espécies iniciais da sucessão ecológica, havendo, porém, restrições de espécies mais avançados (MARTINS, 2009a). Em outros estudos em florestas secundárias (MARTINS et al., 2008), também foi observado uma maior proporção de espécies pioneiras no banco de sementes.

As espécies pioneiras produzem precocemente muitas sementes pequenas, normalmente com dormência, as quais são dispersadas ou por animais (MACEDO, 1993), como em Cecropia spp., e Trema micrantha, por exemplo ou pelo vento (LOPES et al., 2010), como várias espécies das famílias Asteraceae, Malvaceae, entre outras. A dispersão zoocórica é muito importante na manutenção e aumento da fauna dispersora de sementes no início da formação de uma floresta, alavancando o processo de regeneração. As plantas investem em variados recursos como arilos e polpas, atraindo diversos animais que irão dispersar as sementes a grandes distâncias, auxiliando a sucessão secundária de um determinado local (MARTINS, 2009b). Martins et al. (2008) também constatou que a principal síndrome de dispersão em florestas secundárias na Zona da Mata Mineira também foi a zoocórica.

A predominância de espécies anemocóricas na área invadida por $P$. aquilinum é devido a um maior número de indivíduos da samambaia, que possui dispersão anemocórica. Não foi encontrada nenhuma espécie autocórica no banco de sementes da área invadida por $P$. aquilinum e da serapilheira da samambaia.

Silva e Silva-Matos (2006) avaliando o banco de esporos em quatro áreas impactadas na Em relação à dispersão, os três locais apresentaram maior número de espécies zoocóricas, correspondendo a 70,37\% na floresta, 78,57\% na área invadida pela samambaia e 73,33\% na serapilheira observaram que houve diferença estatística significativa entre o número médio de indivíduos de $P$. aquilinum nos quatro locais, sendo que a área mais perturbada apresentou maior número de indivíduos dessa espécie. Dessa forma, esperava-se que na área invadida pela samambaia houvesse uma maior média do número de indivíduos de $P$. aquilinum, tendo em vista que nessa área há uma grande densidade de indivíduos da espécie. É provável que a serapilheira formada pela samambaia esteja impedindo a chegada dos esporos no solo. Mas, isso não é um empecilho para que a espécie se alastre, pois além da reprodução através dos esporos, a rede de rizomas se ramifica profundamente no solo e delas saem os brotos que vão dar origem a um novo indivíduo.

Grombone-Guaratini e Rodrigues (2002) consideraram que a composição de espécies na floresta é influenciada pela comunidade vizinha, o que foi observado nesse estudo, pois apesar de ter sido registrado maior número de indivíduos e de espécies no banco de sementes da floresta, observou-se que $P$. aquilinum está 
invadindo a floresta e contaminando o seu banco, o que pode gerar problemas no futuro, uma vez que $P$. aquilinum possui uma reprodução e dispersão de esporos muito eficientes e frente a um distúrbio ela poderá dominar a área.

Dessa forma, a presença de $P$. aquilinum na floresta, aliada a baixa densidade de indivíduos arbustivoarbóreos comparando-se com as gramíneas e demais herbáceas, indica que o potencial de regeneração da floresta poderá ser reduzida, caso haja uma perturbação mais severa. Silva e Silva-Matos (2006) estudando quatro áreas com diferentes históricos de fogo, no Parque Nacional da Tijuca, no estado do Rio de Janeiro, também mostraram que $P$. aquilinum está se expandindo para dentro da floresta. A presença de $P$. aquilinum na floresta, também indica que o solo desse ambiente não deverá ser utilizado para restauração de áreas degradadas do Parque Nacional do Caparaó, pois poderão contaminar outras áreas do Parque.

Em relação ao índice de equabilidade (J'), o valor encontrado para floresta $(0,77)$ indicou heterogeneidade florística e baixa dominância ecológica. Mas, os valores encontrados para a área invadida pela samambaia $(0,44)$ e para a serapilheira $(0,32)$ mostrou que a área é floristicamente homogênea, com elevada dominância ecológica, o que possibilita inferir que há dominância ecológica mais pronunciada de $P$. aqilinum nessa área, ou seja, há maior concentração de indivíduos dessa espécie no banco. Dentre os indivíduos identificados, na área invadida por $P$. aquilinum (arbustivo-arbóreos e P. aquilinum), $70 \%$ pertencem a $P$. aquilinum.

Tanto Casearia sylvestris como Cecropia hololeuca são espécies pioneiras, produzem grande quantidade de sementes com dimensões reduzidas e possui dispersão zoocórica, o que pode explicar a dominância dessas espécies no banco de sementes da floresta deste estudo. Entre as principais espécies arbóreas pioneiras amostradas por Vinha (2011), no banco de sementes de floresta Estacional semidecídua, também estão Miconia cinnamomifolia, Leandra sp., Cecropia sp., Casearia sylvestris e Piper sp.

Entre as famílias em destaque amostradas nesse estudo, Salicaceae, Urticaceae, Piperaceae, Solanaceae e Melastomataceae também obtiveram destaque em outros estudos em Floresta Estacional Semidecidual na zona da mata mineira (SILVA; SILVA-MATOS, 2006; MARTINS et al., 2008).

É importante ressaltar que na floresta há alta densidade da família Dennstaedtiaceae (4ºgar) e da espécie $P$. aquilinum ( $3^{\circ}$ lugar), mas quanto à frequência a família Dennstaedtiaceae ficou em $8^{\circ}$ e a espécie $P$. aquilinum ficou em $7^{\circ}$ lugar. Isto pode ser explicado pelo fato do banco de sementes ter sido coletado de forma aleatória, sendo que as amostras mais próximas da borda da floresta são mais propensas a contaminação pelos esporos de $P$. aquilinum.

Silva e Silva-Matos (2006) estudando quatro áreas com diferentes históricos de fogo, na Mata Atlântica, também verificaram que a família mais numerosa em todos os locais de estudo, exceto no mais preservado, foi a Dennstaedtiaceae, representada exclusivamente por $P$. aquilinum.

A presença representativa da família Melastomataceae no banco de sementes também foi observada em outra área invadida por P. aquilinum (RIBEIRO et al., 2013), e pode ter sido influenciada pela grande produção de sementes que em geral possuem pequenas dimensões, havendo uma maior possibilidade de vencerem a barreira imposta pela serapilheira e atingirem o solo.

\section{CONCLUSÕES}

- O potencial de regeneração da área invadida por $P$. aquilinum está comprometido, pois houve redução significativa do número de espécies arbóreas e grande número de espécies herbáceas no banco de sementes dessa área, comparando-se com a floresta no entorno.

- A densa camada de serapilheira da samambaia formada na área invadida por P. aquilinum está impedindo a chegada de propágulos e a germinação das poucas sementes presentes no solo, inibindo a sucessão secundária. Portanto, a retirada da serapilheira e a aplicação de técnicas de restauração são medidas importantes para promover a restauração ecológica desse ambiente.

- A presença de P. aquilinum no banco de esporos da floresta no entorno é um indicativo que após a ocorrência de um distúrbio na mesma, esta espécie poderá dominar a área.

\section{REFERÊNCIAS}

APG III - Angiosperm Phylogeny Group III. An update of the Angiosperm Phylogeny Group classification for the orders and families of flowering plants. Botanical Journal of the Linnean Society, v. 161, n. 2, p. 105-121, 2009.

BAIDER, C.; TABARELLI, M.; MANTOVANI, W. The soil seed bank during atlantic forest regeneration in southeast Brazil. Revista Brasileira de Biologia, São Paulo, v. 61, n. 1, p. 35-44, 2001. 
ESTEVES, L. M. Bancos de Esporos de Samambaias e Licófitas: uma Revisão. Anuário do Instituto de Geociências, Rio de Janeiro, v. 36, n. 1, p. 72-79, 2013.

GROMBONE-GUARATINI, M. T.; RODRIGUES, R. R. Seed bank and seed rain in a seasonal semi-deciduous forest in south-eastern Brazil. Journal of Tropical Ecology, Cambridge, v. 18, n. 2, p. 759-774, 2002.

INSTITUTO BRASILEIRO DE GEOGRAFIA E ESTATÍTICA (IBGE). Manual Técnico da Vegetação Brasileira. Rio de Janeiro. 2015. Disponível em < biblioteca.ibge.gov.br> Acesso em: 01 de dez. 2015.

INSTITUTO INSTITUTO CHICO MENDES DE CONSERVAÇÃO DA BIODVERSIDADE (ICMBio). Plano de Manejo Parque Nacional de Caparaó. Brasília. 2015.

LOPES, S. F.; OLIVEIRA, A. P.; NEVES, S. B.; SCHIAVINI, I. Dispersão de sementes de uruvalheira (Platypodium elegans vog.) (Fabaceae) em um cerradão, Uberlândia-MG. Revista Árvore, Viçosa, v. 34, n. 5, p. 807-813, 2010.

MACEDO, A. C. Revegetação: Matas ciliares e de proteção ambiental. São Paulo: Fundação Florestal, 1993. 27 p.

MARTINS, S. V.; ALMEIDA, D. P.; FERNANDES, L. V.; RIBEIRO, T. M. Banco de sementes como indicador de restauração de uma área degradada por mineração de caulim em Brás Pires, MG. Revista Árvore, Viçosa, v. 32, n. 6, p. 1081-1088, 2008.

MARTINS, S. V. Recuperação de áreas degradadas: ações em áreas de preservação permanente, voçorocas, taludes rodoviários e de mineração. Viçosa, MG: Editora Aprenda Fácil, 2009a. 270 p.

MARTINS, S. V. Soil seed bank as indicator of forest regeneration potential in canopy gaps of a semideciduous forest in Southeastern Brazil. In: FOURNIER, M.V. (Ed.). Forest regeneration: ecology, management and economics. New York: Nova Science Publishers, 2009b. p. 113-128.

RIBEIRO, S. C.; BOTELHO, S. A.; FONTES, M. A. L.; GARCIA, P. O.; ALMEIDA, H. S. Regeneração natural em áreas desmatadas e dominadas por Pteridium aquilinum (L.) Kuhn. na Serra da Mantiqueira, Cerne, Lavras, v. 19, n. 1, p. 2013.

SHEPHERD, G. J. Fitopac 2.1 - Campinas, Departamento de Botânica, Universidade Estadual de Campinas, 2010.

SILVA, U. S. R.; SILVA-MATOS, D. M. The invasion of Pteridium aquilinum and the impoverishment of the seed bank in fire prone areas of Brazilian Atlantic Forest. Biodiversity and Conservation, London, v. 15, n. 9, p. 3035-3043, 2006.

STATSOFT, INC. Statistica - Data analysis software system. Version 7.0.61.0. Tulsa, OK 74104, USA, 2007.

TAYLOR J. A. Bracken, an increasing problem and a threat to health. Outlook Agricultural, London, v. 10, n. 6, p. 298-304, 1980.

VINHA, D.; ALVES, L. F.; ZAIDAN, L. B. P.; GRAMBONE-GUARATINI, M. T. The potential of the soil seed bank for the regeneration of a tropical urban forest dominated by bamboo. Landscape and Urban Planning, Amsterdam, v. 99, n. 2, p. 178-185, 2011. 